\title{
HOGEMANN, OS DIREITOS HUMANOS E O UBUNTU
}

HOGEMANN, HUMAN RIGHTS AND THE UBUNTU 


\title{
HOGEMANN, OS DIREITOS \\ HUMANOS E O UBUNTU
}

HOGEMANN, HUMAN RIGHTS AND THE UBUNTU

\author{
Resenha do livro: / Book review: \\ HOGEMANN, Edna Raquel. Direitos humanos e filosofia ubuntu. \\ Rio de Janeiro: Lumen Juris, 2017. (150 p.)
}

RAFAEL SALATINI
Currículo Lattes: http://lattes.cnpq.br/0509507782075890
ORCID: https://orcid.org/0000-0002-7032-134X
E-mail: rafael.salatini@unesp.br
Docente na Unesp (Campus de Marilia)

O livro Direitos humanos e filosofia ubuntu, escrito pela jurista brasileira Edna Raquel Hogemann, fruto do pós-doutoramento realizado pela autora na Universidade Estácio de Sá (RJ) em 2016, se dedica a uma crítica à concepção tradicional (liberal e universalista) de direitos humanos e a defesa da reconstrução conceptiva desses direitos em função da filosofia comunitarista sul-africana do ubuntu.

No primeiro capítulo, a autora discute a construção eurocêntrica dos direitos humanos, argumentando que a origem dos direitos humanos remonta a diversos processos e doutrinas ocidentais, que incluem o estoicismo antigo, o cristianismo medieval e o Iluminismo moderno, em especial a ideia de dignidade humana renascentista e a ideia de autonomia individual iluminista, que se consagrarão na positivação dos direitos de igualdade e liberdade nas grandes declarações de direito dos séculos XVII e XVIII. A autora afirma a subsunção dos direitos humanos aos princípios dos direitos naturais, do racionalismo e do capitalismo modernos, que alimentam a ipseidade, e não a alteridade, humana.

Segundo a autora, "[a modernidade] provocou profundas mudanças na realidade social, com repercussão em todos os quadrantes da vida cotidiana do indivíduo e, num plano mais amplo, da sociedade", de modo que "essas transformações foram promovidas de modo 
descompassado, sem o controle do próprio sujeito, inseridas num processo cujo controle se deu de forma heterônoma" (p. 08).

Os direitos humanos foram promulgados internacionalmente pela Organização das Nações Unidas, em 1948, em resposta à descoberta das atrocidades humanitárias da Segunda Guerra Mundial, consagrados em documentos como a Declaração Universal dos Direitos Humanos (1948), e, posteriormente, o Pacto Internacional dos Direitos Civis e Políticos (1966), o Pacto Internacionais de Direitos Econômicos, Sociais e Culturais (1966) e seus protocolos facultativos, além da Declaração de Viena e do Programa de Ação de Viena (1993), frutos da Conferência Mundial sobre os Direitos Humanos. Soma-se a esse processo a criação de jurisdições regionais para os direitos humanos, como a Corte Europeia dos Direitos Humanos, a Comissão Africana dos Direitos Humanos e das Pessoas e a Corte Interamericana de Direitos

\section{Humanos.}

A autora faz referência à contradição entre a produção de dispositivos normativos humanitários do século XX e o desrespeito sistemático a esses mesmos dispositivos, além da preferência pelos direitos civis e políticos, "sem custos", aos direitos econômicos e sociais, "com custos", e a variedade cultural mundial.

Também faz referência ao conteúdo culturalmente ocidental, "burguês" e ideológico dos direitos humanos, pelo que já haviam sido repelidos pela URSS e outras nações então socialistas. "Nesse sentido", segundo a autora, "por trás dos discursos de justiça, direitos humanos, democracia, desenvolvimento, e mesmo de multiculturalismo, na retórica moderna, subjaz a lógica colonial de uma epistemologia eurocêntrica" (p. 18) e da doutrina política liberal, baseados em aspectos de relações de poder e conotações raciais.

Postulados como baseados essencialmente no projeto iluminista, os direitos humanos são considerados como submetidos à mesma crise que esse projeto enfrenta contemporaneamente. Critica-se o positivismo jurídico e sua capacidade de se opor às práticas totalitárias do século $\mathrm{XX}$, calcando-se no exemplo da argumentação positivista apresentada pelo agente nazista Otto Adolf Eichmann em seu julgamento promovido em Israel e analisado pela filósofa alemã Hannah Arendt, concluindo-se que "o direito não é sinônimo de lei e esta não é sinônimo de justiça" (p. 41).

Assim, a autora conclui que "é possível refletir no sentido de que o erro da modernidade começa na exclusividade de tutela de direitos pelo Estado, ou seja, a tutela jurisdicional, que representa o monopólio da força" (p. 48).

No segundo capítulo, a autora discute os direitos humanos entre a ética e a política, argumentando que a relativização da modernidade e o reconhecimento dos aspectos nãoeuropeus desse processo é necessário para a reformulação dos direitos humanos. Referindo-se 
a quatro grupos de defensores dos direitos humanos - (1) os doutrinadores convencionais, (2) os constitucionalistas ou conceitualistas, (3) os multiculturalistas ou pluralistas culturais, e (4) os estrategistas políticos ou instrumentalistas -, a autora informa que todos "estão, contudo, unidos na crença da existência de direitos humanos que são básicos" e que "também acreditam que esses direitos humanos deveriam ser promovidos e, onde possível, protegidos pelo Estado" (p. 54).

Em seguida, a autora expõe o pensamento do filósofo grego Cornelius Castoriadis, segundo o qual "está em movimento, ainda que de forma penosa e fragmentária, uma nova sociedade[,] fundada num projeto de autonomia social e individual", considerando-se as "provas [...] [que] poderiam ser encontradas nas revoluções democráticas, nas lutas dos trabalhadores por todo o mundo, no movimento feminista, das minorias culturais, étnicas, regionais [etc.]" (p. 59).

A autora busca, então, discutir três metodologias capazes de promover um diálogo intercultural, contra o paradigma dominante, dos direitos humanos. Em primeiro lugar, a "proposta intermediária" do jurista sudanês Abdullahi An-Na'im, que procura conciliar a concepção universalista de direitos humanos com a cultura islâmica, "avalia[ndo] que a legitimidade cultural do padrão universal de direitos humanos deve ser alcançada tendo em conta um âmbito interno, por meio de discursos culturais internos e, em posteriormente, um âmbito externo, por intermédio de diálogos interculturais" (p. 68).

Em segundo lugar, a autora aborda o "diálogo intercultural" do sociólogo português Boaventura de Souza Santos, que parte da crise do Welfare State e do socialismo para elaborar uma teoria multiculturalista crítica/emancipatória dos direitos humanos, argumentando que, "enquanto forem concebidos como direitos humanos universais em abstrato, os direitos humanos tenderão a operar como localismo globalizado e, portanto, como uma forma de globalização hegemônica", de maneira que, "para poderem operar como forma de cosmopolitismo insurgente, como globalização contra-hegemônica, os direitos humanos têm que ser reconceptualizados como interculturais" (apud p. 72).

Em terceiro lugar, analisa-se a "hermenêutica diatópica" do teólogo e filósofo espanhol Raimon Panikkar, expoente da vertente multiculturalista, segundo a qual "um diálogo intercultural e inter-religioso" seria "uma proposta de uma nova prática, de uma nova atitude em face de desafios cada vez mais difíceis enfrentados pela humanidade, como condições necessárias para pavimentar um caminho que possa levar ao encontro de soluções dos grandes problemas da humanidade, como também para a tão urgente quanto necessária construção de uma paz mundial" (p. 82).

No terceiro capítulo, a autora apresenta a sugestão central do livro: uma interpretação dos 
direitos humanos a partir da filosofia sul-africana ubuntu, baseada nos princípios de participação e da reconciliação, princípio que esteve presente na Constituição transitória da África do Sul (1993) - Mas não fora repetido na Constituição definitiva de 1996 - e na Comissão da Verdade e da Reconciliação (1996), presidida pelo arcebispo anglicano Desmond Mpilo Tutu, tendo sido inclusive absorvido pela Corte Constitucional e pelos tribunais superiores sul-africanos.

Ubuntu é uma expressão sul-africana pré-europeia que frisa a relação de lealdade entre as pessoas, segundo a expressão umuntu ngumuntu ngabantu [uma pessoa é uma pessoa através de outras pessoas]. Com base nesse princípio, segundo a autora, "cada ser humano só é um ser humano por pertencer a um coletivo humano; a humanidade de uma pessoa é determinada pela alteridade com os outros, por meio de sua humanidade para com os outros seres humanos", ou seja, "a existência de uma pessoa se dá por meio da existência dos outros em relação intrínseca consigo mesma, mas o valor de sua humanidade está inteiramente relacionado à forma como ela esteia proativamente a humanidade e a dignidade dos demais seres humanos", ou, ainda, "a humanidade de uma pessoa é, assim, definida por seu compromisso ético com seu próximo, seja ele quem for: homem, mulher, criança, jovem, velho" (p. 90).

A autora discute, então, o conteúdo ético da filosofia ubuntu a partir da contribuição de vários estudiosos e pensadores africanos, comparando com pensadores ocidentais não liberais, como Castoriadis, Ricoeur, Lévinas e Panikkar.

Em suas considerações finais, por fim, a autora reafirma sua crítica à concepção dominante dos direitos humanos ocidentais, baseada nos princípios do universalismo, do racionalismo e do individualismo tipicamente liberais, assim como reafirma a importância da consideração da filosofia comunitarista sul-africana do ubuntu para a rediscussão dos direitos humanos, concluindo com a asserção de que "discutir os direitos humanos desde a lógica presente na ética ubuntu significa colocar em debate o que é bom para mim, para a família, para o povo, para aqueles que conduzem os destinos das nações" (p. 135).

O debate entre liberais (defensores de uma concepção universal de direitos humanos) e comunitaristas (defensores de uma concepção multicultural de direitos humanos) tem se desenvolvido grandemente, sem um horizonte visível de solução, especialmente entre estudiosos norte-americanos e europeus. A contribuição brasileira de Edna Raquel Hogemann, partidária do segundo grupo, com base na filosofia do ubuntu pode ser considerada como uma contribuição eminentemente originária dos interesses e das referências pertencentes aos países em desenvolvimento (caso tanto do Brasil quanto da África do Sul), sentido em que ganha grande importância e desvia ao menos uma parte do debate norte-atlântico para o comunitarismo africano (numa leitura brasileira), aumentando a abrangência das discussões humanitárias para onde eventualmente elas sejam mais necessitadas. 


\section{SOBRE O AUTOR:}

\section{Rafael Salatini}

Bacharel em Ciências Sociais (USP), Licenciado em Ciências Sociais (USP), Bacharel em Direito (Univem), Especialista em Direito Processual Civil (Unimar), Especializando em Direito Penal e Processual Penal (Única), Especializando em Direito Penal e Processual Penal (Una), Mestre em Direito (Univem), Doutor em Ciência Política (USP), Doutorando em Ciência Jurídica (UENP), Pós-doutor em Sociologia (USP) e Pós-doutor em Ciência Política (USP).

\section{DESC

